Citation: Tombor, I., Michie, S. (in press). Methods of Health Behaviour Change. In Oxford Research Encyclopedia of Psychology. Ed. Oliver Braddick. New York: Oxford University Press, forthcoming.

\title{
Methods of Health Behavior Change
}

\author{
Summary \\ People's behavior influences health, for example, in the prevention, early detection, and \\ treatment of disease, the management of illness, and the optimization of healthcare \\ professionals' behaviors. Behaviors are part of a system of behaviors within and between \\ people in that any one behavior is influenced by others. Methods for changing behavior may \\ be aimed at individuals, organizations, communities, and/or populations and at changing \\ different influences on behavior, e.g., motivation, capability, and the environment. A \\ framework that encapsulates these influences is the Behavior Change Wheel, which links an \\ understanding of behavior in its context with methods to change behavior. Within this \\ framework, methods are conceptualized at three levels: policies that represent high-level \\ societal and organisational decisions, interventions that are more direct methods to change \\ behavior, and behavior change techniques that are the smallest components that on their own \\ have the potential to change behavior. In order to provide intervention designers with a \\ systematic method to select the policies, interventions, and/or techniques relevant for their \\ context, a set of criteria can be used to help select intervention methods that are likely to be \\ implemented and effective. One such set is the "APEASE" criteria: affordability, \\ practicability, effectiveness, acceptability, safety, and equity.
}

\section{Keywords}


health behaviors, population health, frameworks of behavior change, Behavior Change Wheel, methods to behavior change, policies, interventions, behavior change techniques, implementation

\section{Health Behavior Change and Population Health}

Health behaviors refer to any behaviors that impact on people's physical and mental health and quality of life. "Behavior" can be defined as "anything a person does in response to internal or external events. Actions may be overt (motor or verbal) and directly measurable or, covert (activities not viewable but involving voluntary muscles) and indirectly measurable; behaviours are physical events that occur in the body and are controlled by the brain" (Davis, Campbell, Hildon, Hobbs, \& Michie, 2015, p. 327). Behaviors are part of a system in that any given behavior is influenced by other behaviors of the same or other individuals (Michie, Atkins, \& West, 2014). Individual behaviors (e.g., lighting up a cigarette or eating an energy-dense snack) are often recurring and thus better described as "behavior patterns" (e.g., smoking, overeating) characterized by aggregated measures such as frequency, duration, intensity, or volume of consumption (Michie et al., 2014). Behaviors are dynamic in that not only do they interact (positively and negatively) with each other, but these relationships change over time. Three types of behavior are related to population health: behaviors that contribute to the prevention of disease, behaviors that involve care-seeking and adherence to treatment, and behaviors that relate to the delivery of healthcare. For behaviors to translate into population health, they must be maintained over the long run and factors influencing maintenance may differ from those influencing initiation of change. This important topic is beyond the scope of this article, but we refer you to publications in this area (Gardner, 2015; Verplanken \& Wood, 2006; Wood \& Rünger, 2016). 
Tobacco smoking, excessive alcohol consumption, physical inactivity, and unhealthy eating are leading contributors to preventable premature death and ill health in high-income countries (AIHW, 2014; Department of Health, 2014; Johnson, Hayes, Brown, Hoo, \& Ethier, 2014). Historically, the overall burden of disease in low-income countries was mainly attributed to infectious diseases as opposed to non-communicable diseases, such as cancer, stroke, heart disease, respiratory disease, and liver disease (World Health Organization, 2009). However, due to the increased prevalence of smoking, alcohol consumption, and obesity, low-income countries have begun to face a huge combined burden from both noncommunicable and infectious diseases (World Health Organization, 2009). In addition to non-communicable diseases, the risks of infectious diseases such as HIV/AIDS can also be reduced or completely prevented by behavior change, such as by using condoms (Holmes, Levine, \& Weaver, 2004).

Behaviors that involve care-seeking and adherence to treatment include taking part in vaccination programs. This can limit the spread of disease such as pandemic or seasonal influenza and childhood infectious diseases (e.g., diphtheria, polio, neonatal tetanus) (CDC, 2013; Hinman, 1999; Rubinstein, Marcu, Yardley, \& Michie, 2015). Moreover, improving adherence to antibiotic therapy among patients (Llor et al., 2013) is important to minimize the development of antimicrobial-resistant infections that contribute to 700,000 deaths each year globally (O’Neill, 2014). If the onset of disease cannot be prevented, early diagnosis of (pre-clinical) conditions and adherence to treatment can improve prognosis. For example, participating in screening programs, such as the U.K. National Health Service bowel cancer screening program, can help identify cancer in the early stages when the prognosis of recovery is potentially much better (Logan et al., 2011). Similarly, engaging with regular monitoring of chronic health conditions (e.g., high blood pressure) and adhering to medications for long-term conditions (e.g., HIV, heart disease) can slow the progression of 
disease and improve patients' quality of life (Ito et al., 2012; Ownby, Waldrop-Valverde, Jacobs, Acevedo, \& Caballero, 2013).

The extent to which the delivery of healthcare is based on evidence is an important contributor to effectiveness and quality of care (Sackett, Rosenberg, Gray, Haynes, \& Richardson, 1996). Changing healthcare professionals' behaviors so that they implement evidence-based guidelines is likely to improve health (Michie et al., 2005). Examples of interventions designed to change healthcare professional behavior include feedback to improve hand-hygiene practices (Fuller et al., 2012), training and education to improve the management of mild brain injury in emergency departments (Tavender et al., 2015), and feedback to reduce unnecessary antibiotic prescribing (Hallsworth et al., 2016).

Effective interventions and policies are needed to tackle population health challenges globally. This will require systematic analyses of the behaviors of those who receive and those who deliver healthcare and a better understanding of potential mechanisms by which change is brought about. Frameworks of behavior and behavior change can be useful for this purpose.

\section{Frameworks for Behavior Change}

Behavior change can be aimed at different levels, including individual, organizational, community, and population levels, and any intervention delivered at one level can impact on other levels. The most effective interventions are those that target several levels simultaneously and consistently (NICE, 2007, 2014). There are a variety of types of methods to bring about behavior change; a review of effective behavior change interventions and recommendations for practice at population, community, and individual levels identified 
evidence-based principles underlying effective behavior change (NICE, 2007). These are (Abraham, Kelly, West, \& Michie, 2009):

1. Knowledge and outcome expectancies (improving people's knowledge about the health consequences of their behaviors)

2. Personal relevance (drawing people's attention to what health behavior change would mean for them)

3. Positive affective attitudes (promoting positive feelings about behavior change)

4. Descriptive norms (increasing the visibility of positive health behaviors in the social environment)

5. Subjective norms (improving social approval of positive health behaviors)

6. Personal and moral norms (promoting personal commitments to behavior change)

7. Self-efficacy (increasing people's belief in their ability to change their behaviors)

8. Intention/Goal setting and the formation of concrete plans (helping people set goals and form plans on how to achieve them)

9. Behavioral contracts (facilitating that people share their plans and goals with others) 10. Social relationships (drawing attention to the social influences on health behaviors) 11. Relapse prevention (helping people develop skills to cope with difficult situations) The updated review and recommendations for interventions aimed at individuals identified good evidence for the effectiveness of goals and planning, feedback and monitoring, and social support (NICE, 2014).

These evidence-based principles of behavior change can be conceptualized in terms of three high-level influences on behavior: capability, opportunity, and motivation. These are encapsulated in the COM-B (Capability, Opportunity, Motivation, Behavior) model (Michie, van Stralen, \& West, 2011). Capability refers to people's physical skills, strength, and 
physical stamina (e.g., having the strength to walk up stairs) and psychological capability such as knowledge, behavioral regulation, psychological skills, mental strength, and stamina (e.g., having knowledge about vaccination programs) to perform the behavior. Motivation involves automatic processes such as habits, emotional states (e.g., having an urge to smoke), and reflective processes such as self-conscious intentions, beliefs, and identity (e.g., having a strong motivation to become more athletic) that energize and direct behavior. Opportunity refers to the social environment involving the cultural milieu, social norms, social influences, and modeling (e.g., having a senior colleague as role model to aspire or imitate) and physical environmental in terms of resources, cues, locations, and time (e.g., being able to access stopsmoking support) that permit the behavior. The COM-B framework proposes that intrapersonal (capability and motivation) and environmental (opportunity) influences on behavior interact in that capability, opportunity, and motivation influence behavior, capability and opportunity influence motivation, and behavior influences all three components. Behavior change therefore requires change in one or more of capability, opportunity, and motivation, and these can serve as targets for behavior change interventions. Table 1 shows how evidence-based principles of behavior change (Abraham et al., 2009) can be conceptualized as one or more of the COM-B components.

\section{<COMP: INSERT TABLE 1 NEAR HERE >}

Three components of the COM-B model (capability, opportunity, and motivation) can be further elaborated by the Theoretical Domains Framework (Cane, O’Connor, \& Michie, 2012; Michie et al., 2005). The Theoretical Domains Framework was originally developed to help intervention designers and policymakers develop theory-based implementation interventions to improve the implementation of research evidence into practice. It consists of 14 domains developed from synthesizing constructs identified in 33 theories (Cane et al., 2012; Michie et al., 2005): 
1. Knowledge

2. Skills

3. Social/Professional role and identity

4. Beliefs about capabilities

5. Beliefs about consequences

6. Goals

7. Memory, attention, and decision processes

8. Environmental context and resources

9. Social influences

10. Emotion

11. Behavioral regulation

12. Optimism

13. Intentions

14. Reinforcement

Components of COM-B map on domains of the Theoretical Domains Framework in that 1) physical capability includes skills; 2) psychological capability includes knowledge, skills, memory, attention, and decision processes and behavioral regulation; 3) social opportunity includes social influences; 4) physical opportunity includes environmental context and resources; 5) automatic motivation includes emotion and reinforcement; and 6) reflective motivation includes goals, intentions, beliefs about consequences, beliefs about capabilities, optimism, and social/professional role and identity (Francis, O’Connor, \& Curran, 2012). Table 2 shows how domains of the Theoretical Domains Framework can be linked with evidence-based principles of behavior change and components of the COM-B model. 


\section{<COMP: INSERT TABLE 2 NEAR HERE >}

The Theoretical Domains Framework provides a method for systematically investigating influences on behavior change (Francis et al., 2012). A large number of studies across various disciplines and settings have used the COM-B and/or the more elaborated Theoretical Domains Framework to identify barriers and enablers to behaviors in order to inform the design of behavior change interventions. Examples include studies focusing on healthcare professionals' behavior in relation to prescribing medications (Duncan et al., 2012; Fleming, Bradley, Cullinan, \& Byrne, 2014; Sinnott et al., 2015) and managing low back pain without unnecessary x-ray referrals (Bussieres, Patey, Francis, Sales, \& Grimshaw, 2012; French et al., 2012). Another example is a study of being vaccinated and taking antiviral medicines, which found that the identity of being a healthy person (reflective motivation, social/professional role and identity) can be a barrier because it evoked feelings of invulnerability and beliefs about being able to fight disease without taking medications (Rubinstein et al., 2015). In terms of facilitators, recommendations from credible sources (social opportunity, social influences) in favor of vaccination was found to increase people's motivation to seek prevention and treatment. These findings suggest that interventions to promote engagement with vaccination programs could include communications that challenge these identity beliefs and that explain how vaccination can boost immunity for everyone.

\section{The "Nudge" Approach}

A group of methods that has attracted wide attention over the last decade is summarized in the book Nudge: Improving Decisions About Health, Wealth and Happiness (Thaler \& Sunstein, 2008). These "nudge" methods have been applied by national governments in the 
United Kingdom and the United States (Cabinet Office Behavioural Insights Team, 2010; Local Government Association, 2013; Matjasko, Cawley, Baker-Goering, \& Yokum, 2016). They are defined as "any aspect of the 'choice architecture' that alters people's behaviour in a predictable way without forbidding any options or significantly changing their economic incentives" (Thaler \& Sunstein, 2008, p. 5). They take a "libertarian paternalist" stance regarding human behavior, suggesting that the government can influence people in their best interests as long as the influence is non-intrusive and people's freedom of choice is retained (Thaler \& Sunstein, 2008). One of its key concepts, which is rooted in behavioral economics, is that it focuses on how people make decisions and how changes in the environment where the different choices are presented (e.g., healthy snacks versus chocolate bars in shops) can help them make choices that will improve their health (Matjasko et al., 2016; Thaler \& Sunstein, 2008).

Typically, "nudge" interventions include environmental restructuring (e.g., placing healthy food closer to the counter), modeling (e.g., drawing attention to others' behavior in the social group), and (non-financial) incentivization (e.g., provide collectable badges in digital interventions), all effective in influencing behavior in certain circumstances (Marteau, Ogilvie, Roland, Suhrcke, \& Kelly, 2011; Matjasko et al., 2016; Michie \& West, 2013). However, they do not include interventions, such as financial incentivization, restrictions, and coercion (e.g., fines for transgressions) or policies such as legislation, regulation and fiscal measures (House of Lords, 2011; Marteau et al., 2011; Michie \& West, 2013).

Limiting interventions in this way restricts their effectiveness and cost-effectiveness for equitable public health (Marteau et al., 2011; Michie \& West, 2013) and raises questions about the ideological reasons for these constraints (e.g., giving industry freedoms to make profits at the expense of public health) (Baldwin, 2014; Bonell, McKee, Fletcher, Wilkinson, \& Haines, 2011). A national report on behavior change concluded that it also limited the 
usefulness of behavior change interventions for national government (House of Lords, 2011). For example, countries that introduced legislation to reduce the salt content in foods achieved five times higher reduction in adults' daily salt consumption, a well-known contributor to high blood pressure, than the United Kingdom, where a different approach was taken involving negotiations with the food industry with only a threat of potential legislation (Cappuccino \& Capewell, 2010).

Changing people's behavior on a population scale requires intervention strategies that operate at many levels (individual, organizational, community, population) and use a variety of methods simultaneously in order to target different influences on behavior (BMA, 2012; House of Lords, 2011; Michie \& West, 2013; NICE, 2007, 2014). An integrative framework for intervention development that provides a comprehensive range of interventions and policies can inform decisions regarding the most appropriate methods to bring about behavior change.

\section{An Integrative Framework for Designing Behavior}

\section{Change Interventions: The Behavior Change Wheel}

The Behavior Change Wheel is a synthesis of 19 frameworks of behavior change identified in a systematic literature review (Michie, van Stralen, \& West, 2011). They include widely used frameworks such as “intervention mapping” (Bartholomew, Parcel, Kok, Gottlieb, \& Fernandez, 2011) and "MINDSPACE" (Institute for Government, 2010); the full list and details of the synthesis process can be found in the supplementary files of Michie et al. (2011). These frameworks were evaluated against three criteria that were deemed to be essential characteristics of their usefulness to inform intervention development: conceptual coherence, comprehensive coverage of intervention types, and linkage to a model of 
behavior. A conceptually coherent framework includes categories of the same type and specificity of entity, and a comprehensive framework offers the full range of potential types of interventions for intervention designers to consider. The third criterion encapsulates the importance for a framework to provide a system whereby one can formally analyze the target behavior based on a theoretical model and systematically select intervention types depending on what influences need to be changed to achieve behavior change. Since none of the frameworks met all three criteria and there was overlap between them, an integrative framework was developed from the 19 frameworks (Michie, van Stralen, \& West, 2011).

\section{<COMP: INSERT FIGURE 1 NEAR HERE>}

The Behavior Change Wheel (Figure 1) has the COM-B model at its hub surrounded by two rings of intervention strategies. The first ring has nine intervention functions that are direct methods for changing behavior, with the outer ring being seven policy categories which are high-level societal and organizational strategies for implementing and sustaining behavior change. Each intervention function reflects many different behavior change techniques; these are the smallest intervention components that on their own have the potential to change behavior (Michie et al., 2014; Michie \& Johnston, 2013).

The Behavior Change Wheel provides a systematic guide for designing behavior change interventions (Michie et al., 2014; Michie, van Stralen, \& West, 2011). It has been used widely across a range of behavioral domains, settings, and problems. Examples include interventions designed to increase engagement with face-to-face smoking cessation support among adults (Fulton, Brown, Kwah, \& Wild, 2016), aid smoking cessation among pregnant women (Tombor et al., 2016), improve childhood weight management among parents (Curtis, Lahiri, \& Brown, 2015), promote attentive eating among overweight and obese adults (Robinson et al., 2013), reduce cardiovascular disease risk among people with severe mental illness in primary care (Osborn et al., 2016), improve the implementation of upper limb 
exercise in stroke rehabilitation (Connell, McMahon, Redfern, Watkins, \& Eng, 2015) and improve general practitioners' management of long-term medications (Sinnott et al., 2015).

Selecting effective strategies for behavior change needs to be based on a clear understanding of which behaviors are likely to be most easy to change with greatest impact. This decision should be informed by a "behavioral diagnosis." A behavioral diagnosis starts with defining the problem that the intervention aims to address (e.g., to reduce childhood obesity) in behavioral terms (e.g., improving children's diet, increasing their physical activity etc.). For each key candidate behavior, one needs to define the behavior very precisely in terms of who needs to do what differently, when, where, with whom, and how. For example, in order to improve children's diet, one may suggest that parents need to pack fruits and vegetables in children's lunchbox every day instead of snacks, or that children need to cut down their daily sugary drink consumption, or that healthcare professionals need to support parents in managing their children's diet, or that teachers need to include the topic of healthy eating in the school curriculum. Behaviors tackled at policy level include additional categories of people whose behavior is relevant to the target behavior. For example, for food consumption, relevant people would include those involved in the food industry, commissioners of health and social services, town planners, policymakers within local and national government, etc. Given that any behavior is influenced by other behaviors within and between people, both positive and negative "spillover" effects and the significance of these consequences need to be considered.

After specifying the target behavior and population in as much detail as possible (e.g., to help parents pack fruits and vegetables in children's lunchbox every day instead of snacks), the next step in the behavioral diagnosis involves using the COM-B model or the Theoretical Domains Framework to investigate what needs to be changed in people and/or the environment to bring about behavior change (Francis et al., 2012; Michie et al., 2014; 
Michie, van Stralen, \& West, 2011). A thorough assessment of behavior draws on different sources. This can include evidence from the scientific literature, findings from formal research, and less formal data gathering conducted with people from the target population, stakeholders, and experts in relevant fields by means of interviews, focus groups, and questionnaires (Francis et al., 2012). A behavioral diagnosis contributes to a better understanding of the nature of the target behavior in terms of the intrapersonal (e.g., parents' knowledge and beliefs about what constitutes a "healthy lunchbox") and environmental influences on its development (e.g., influences of what other parents in the social environment pack in their children's lunchbox), maintenance, and predicted levers for future change. This can inform decision-making regarding the interventions and policies that are likely to be effective in a given context (Michie et al., 2014; Michie, van Stralen, \& West, 2011).

Within the Behavior Change Wheel, each of the nine intervention functions refers to a general method by which an intervention can change behavior (Michie et al., 2014; Michie, van Stralen, \& West, 2011), and these can be linked with evidence-based principles of behavior change (Table 3). The intervention functions are:

1. Education (e.g., increasing parents' knowledge about the importance of a healthy diet) 2. Persuasion (e.g., inducing positive feelings to pack fruits and vegetables in children's lunchbox)

3. Incentivization (e.g., creating expectation of financial or other rewards if one packed fruits and vegetables in the child's lunchbox every day)

4. Coercion (e.g., increasing the cost of salty food and snacks)

5. Training (e.g., providing training to parents to improve their skills to cook with healthy ingredients)

6. Restriction (e.g., using rules to reduce purchasing of energy-dense food) 
7. Environmental restructuring (e.g., using prompts in shops to increase the attractiveness of fruits and vegetables)

8. Modeling (e.g., providing an example for parents to aspire or imitate when managing their children's diet)

9. Enablement (e.g., providing behavior support for weight management)

For example, a behavioral diagnosis may indicate that increasing parents' reflective motivation (e.g., their beliefs, intentions, and plans) is one of the important factors to be targeted in interventions aimed at increasing the fruit and vegetable content of children's lunchbox. One can then draw on the Behavior Change Wheel to identify the intervention functions relevant to changing these: education, persuasion, incentivization, and modeling.

<COMP: INSERT TABLE 3 NEAR HERE>

Depending on the intervention functions selected, the Behavior Change Wheel points to seven policy categories to enable or support the interventions (Michie et al., 2014; Michie, van Stralen, \& West, 2011). These are:

1. Communication and marketing (e.g., distributing leaflets and organizing mass media campaigns to promote a healthy diet)

2. Guidelines (e.g., establishing protocols for what constitutes a healthy lunchbox for children)

3. Fiscal measures (e.g., implementing higher tax on snacks)

4. Regulation (e.g., prohibiting vending machines on school premises)

5. Legislation (e.g., introducing laws to ban added sugar in foods marketed for children)

6. Environmental and social planning (e.g., providing easy access to healthy food items in the localities) 
7. Service provision (e.g., establishing digital healthcare services to help parents keep track of their children's diet)

For example, interventions focusing on modeling to change behavior may be supported by policies involving communication and marketing activities and service provision. Definitions of the intervention functions and policy categories are provided in Michie, van Stralen, \& West (2011) and Michie et al. (2014).

Intervention functions can be put into practice by a large number of behavior change techniques; 93 have been identified and organized into a taxonomy in an international project (Michie et al., 2013, 2015). For more information about these techniques, see Michie et al. (2014, p. 145), *online training[http://www.bct-taxonomy.com]*, and a smartphone app that can be found by searching "BCT taxonomy" in the app stores. Intervention designers can use systematic methods to identify which behavior change techniques are likely to be the most appropriate given their target behavior/s, population, setting, and intervention constraints (Michie et al., 2014).

\section{Behavior Change Techniques and Taxonomies}

Behavior change interventions are complex, at least in part, because they include many interacting components (Craig et al., 2008). Specifying interventions by behavior change techniques improves the precise reporting of the content of complex interventions so that they can be evaluated, delivered with fidelity, replicated, and generalized to different contexts. Using a shared language when describing intervention content can facilitate this process, and taxonomies of behavior change techniques have been developed with agreed labels and definitions. For example, “action planning" must include detailed planning of performance of the behavior in terms of at least one of context, frequency, duration, or intensity (Michie et al., 2013). 
Several taxonomies have been developed for specific behavioral domains including physical activity and healthy eating (Abraham \& Michie, 2008; Michie, Ashford, et al., 2011), smoking cessation (Michie, Hyder, Walia, \& West, 2011; West, Evans, \& Michie, 2011), reducing excessive alcohol consumption (Michie et al., 2012), and increasing condom use (Abraham, Good, Huedo-Medina, Warren, \& Johnson, 2012). Building on these taxonomies, the Behavior Change Techniques Taxonomy v1 (BCTTv1) was developed by an international consensus of 400 experts from 12 countries. It includes 93 distinct behavior change techniques that are hierarchically structured and clustered into 16 higher-order groups (Michie et al., 2013, 2015).

An empirical approach, involving open-sort grouping tasks and hierarchical cluster analysis, was used to group behavior change techniques in the BCTTv1 (Michie et al., 2013, 2015). The structure of each higher-order grouping containing similar behavior change techniques in terms of their mechanisms of change can aid easier recall of behavior change techniques and the practical use of the taxonomy. Behavior change techniques in the BCTTv1 can also be reliably linked to domains from the Theoretical Domains Framework. There is a moderate overlap between higher-order groups and theoretical domains. Both of these and the simpler COM-B model can aid the selection of behavior change techniques to inform theory-based intervention development, which is used by researchers appears to reflect personal preference and past practice. Higher-order groups with example behavior change techniques are:

1. Goals and planning (e.g., "goal setting")

2. Feedback and monitoring (e.g., "self-monitoring of behavior")

3. Social support (e.g., "social support, practical”)

4. Shaping knowledge (e.g., "instruction on how to perform a behavior")

5. Natural consequences (e.g., "information about health consequences") 
6. Comparison of behavior (e.g., "social comparison")

7. Associations (e.g., "prompts/cues")

8. Repetition and substitution (e.g., "behavioral practice/rehearsal")

9. Comparison of outcomes (e.g., "pros and cons")

10. Reward and threat (e.g., "material reward, behavior")

11. Regulation (e.g., "pharmacological support")

12. Antecedents (e.g., "adding objects to the environment")

13. Identity (e.g., "valued self-identity”)

14. Scheduled consequences (e.g., "behavior cost")

15. Self-belief (e.g., "self-talk")

16. Covert learning (e.g., "imaginary reward")

Evidence regarding the effectiveness of behavior change techniques is accumulating for different behaviors and populations, for example, to improve dietary behaviors (Lara et al., 2014), increase sedentary behavior (Gardner, Smith, Lorencatto, Hamer, \& Biddle, 2016), and aid physical activity among healthy and overweight adults (Williams \& French, 2011), obese adults (Olander et al., 2013), and older adults (French, Olander, Chisholm, \& Sharry, 2014). There is some evidence to suggest that interventions that use more behavior change techniques are more effective than those that use fewer behavior change techniques (Gardner et al., 2016; Webb, Joseph, Yardley, \& Michie, 2010).

Behavior change techniques may yield greater effects if they are delivered in theoretically informed groups rather than in isolation. An effective combination of behavior change techniques that work synergistically together is self-monitoring with goal-setting, action planning, and/or feedback on behavior (Dombrowski et al., 2012; Michie, Abraham, Whittington, McAteer, \& Gupta, 2009). Also, problem-solving has been found to be more 
effective in combination with providing rewards for behavior (van Genugten, Dusseldorp, Webb, \& van Empelen, 2016). A third example is that although using threatening communications about health risks has been advocated to change behavior, such as to aid smoking cessation (Borland et al., 2009), its effectiveness has been found to be greater if it is paired with increasing people's confidence to change ("self-efficacy") (Peters, Ruiter, \& Kok, 2013).

Relevant research evidence is an important criterion for selecting behavior change techniques for a given behavior, population, and setting. However, there are other criteria to be considered when selecting behavior change techniques that are likely to increase the implementation of interventions.

\section{Systematic Context-Based Decision-Making About Behavior}

\section{Change Interventions: The APEASE Criteria}

The process of intervention development is likely to generate a large number of possible intervention functions, behavior change techniques, and policy categories. However, it may not be possible or appropriate to implement all of these given the context and limitations such as the mode of delivery of the intervention and resources, and thus decisions have to be made as to which methods to include based on explicit reasons (Michie et al., 2014).

The APEASE (Affordability, Practicability, Effectiveness and cost-effectiveness, Acceptability, Safety and side effects, Equity) criteria have been developed to help intervention developers and policymakers follow a systematic decision-making process when designing behavior change interventions (Michie et al., 2014). "Affordability” refers to interventions being designed and delivered within a specified budget and accessed by people from the target population. "Practicability" refers to whether it is feasible to deliver the intervention as intended. "Effectiveness" refers to whether the intervention is effective in 
relevant real-world contexts. This should be judged based on evidence primarily from highquality randomized controlled trials and experimental and observational studies. When considering the implementation of effective interventions, more weight should be given to the more cost-effective ones. "Acceptability" refers to whether the intervention is likely to be acceptable to relevant stakeholders, including people from the target population, policymakers, healthcare professionals, funding agencies, and national governments. The criterion of "safety and side effects" refers to the possible unwanted or unintended consequences of an effective intervention. A behavior change intervention meets the criterion of "equity" to the extent that it reduces the disparities between different groups of society and provides equal access to the intervention across the social spectrum.

Although APEASE provides a structured way of assessing intervention methods, intervention designers and policymakers need to draw on local knowledge and their own expertise when selecting the most appropriate intervention functions, behavior change techniques, and policies to be implemented in a given context. The criteria will be illustrated in relation to interventions to increase smoking cessation.

There is ample evidence that the most effective treatments for tobacco dependence are those that combine pharmacotherapy with behavioral support provided by smoking cessation specialist advisors (Kotz, Brown, \& West, 2013; Stead \& Lancaster, 2012). Although these are both effective and cost-effective interventions (APPG, 2010; West, May, West, Croghan, \& McEwen, 2013), some of the more expensive smoking cessation medications (e.g., varenicline) and multi-session counseling may not be globally affordable, especially in lowincome countries (West et al., 2015). On the other hand, brief opportunistic smoking cessation advice from healthcare professionals, proactive telephone support, text messaging interventions, printed self-help materials, and some forms of pharmacotherapy (e.g., cytisine) are also effective and appear to be globally affordable to aid cessation (West et al., 2015). 
In terms of practicability, effective behavior change techniques, such as providing feedback on smokers' expired carbon monoxide readings (Shahab, West, \& McNeill, 2011), may be considered as more feasible if delivered face-to-face rather than via digital interventions (Tombor, Neale, Shahab, Ruiz, \& West, 2015).

Providing financial incentives for smoking cessation in pregnancy has been found to be effective and highly cost-effective, and therefore it may be considered in high-income countries as a valuable addition to existing public health services (Boyd, Briggs, Bauld, Sinclair, \& Tappin, 2015; Higgins et al., 2012; Lumley et al., 2009; Tappin et al., 2015).

In terms of acceptability, it has been found that a third of current smokers in England would support a total ban on sale of tobacco products (Shahab \& West, 2010). However, if this is not aligned with national governmental objectives, the intervention is unlikely to be supported by relevant policies.

Providing financial incentives is effective in increasing smoking cessation rates among pregnant smokers (Tappin et al., 2015); however, unintended consequences have been identified including creating distrust between healthcare professionals and clients and increasing the negative public perception of pregnant smokers (Thomson et al., 2014). It is important to identify potential negative consequences, and it needs to be considered whether the expected benefits of a behavior change intervention would be likely to outweigh its potential risks.

Smokers from low-socioeconomic groups are less likely to stop smoking than smokers from high socioeconomic groups (Kotz \& West, 2009). Even though they are motivated to quit (Kotz \& West, 2009), smokers from disadvantaged backgrounds are less likely to attend face-to-face support and use pharmacotherapy for long enough to aid cessation (ASH, 2016; Hiscock \& Bauld, 2013). Improving equity of access to, and use of, effective smoking cessation support requires interventions to meet the needs of smokers across the social 
spectrum and target deprived communities where smoking prevalence is the highest (ASH, 2016; Hiscock \& Bauld, 2013).

The APEASE criteria have been used to inform the development and evaluation of behavior change interventions in various settings, such as to improve antibiotic prescribing in long-term care facilities (Fleming et al., 2014), improve the routine delivery of caries prevention and management in primary dental care (Templeton et al., 2015), optimize general practitioners' medication management for patients with multiple chronic conditions (Sinnott et al., 2015), select modes of delivery for an intervention targeting multiple health behaviors among students (Tzelepis et al., 2015), and modify an existing evidence-based intervention for sepsis treatment in order to improve its implementation (Steinmo et al., 2016).

\section{Future Directions}

For policymakers, intervention designers and researchers, a key question is: What behavior change interventions work, how well, for whom, in what settings, for what behaviors and why? To assist in this, future work is building an "ontology" of behavior change interventions (Larsen et al., 2016). Ontologies provide systematic and efficient methods for generating organized structures of knowledge base. An ontological framework comprises clearly defined key concepts (“classes") (e.g., intervention, mechanisms of action, intervention usage, context, and behavior) and the relationship between them. Classes and relationships are specified using controlled vocabularies (e.g., the BCTTv1 can be used to specify behavior change techniques) and codified in a computer-readable format (Larsen et al., 2016). *The Human Behaviour-Change Project [http://www.humanbehaviourchange.org]* is a collaboration between behavioral scientists, information scientists and computer scientists. This multi-disciplinary team aims to build an 
artificial intelligence system that will continually scan the scientific literature on behavior change, identify key information using natural language processing and machine learning, and extract relevant information into the Behavior Change Intervention Ontology.

Knowledge generated in this project through the evidence synthesis can provide a basis for a better understanding of human behavior and effective methods to achieve behavior change beyond the context of individual studies. The system will be accessible to researchers, intervention designers, and policymakers so that they can obtain up-to-date evidence of effective methods to change particular behaviors given the target population and context. The Human Behaviour-Change Project will accumulate evidence on behavior change more efficiently and rapidly and contribute to designing more effective interventions tailored to behaviors, populations, and contexts.

\section{References}

Abraham, C., Good, A., Huedo-Medina, T., Warren, M., \& Johnson, B. (2012). *Reliability and utility of the SHARP Taxonomy of Behaviour Change Techniques. EHPS 2012 abstracts. [http://dx.doi.org/10.1080/08870446.2012.707817]* Psychology \& Health, 27 (Supplement 1), 1-357.

Abraham, C., Kelly, M. P., West, R., \& Michie, S. (2009). *The UK National Institute for Health and Clinical Excellence Public Health Guidance on behaviour change: A brief introduction[http://dx.doi.org/10.1080/13548500802537903]*. Psychology, Health and Medicine, 14(1), 1-8.

Abraham, C., \& Michie, S. (2008). *A taxonomy of behavior change techniques used in interventions[http://dx.doi.org/10.1037/0278-6133.27.3.379]*. Health Psychology, 27(3), $379-387$.

AIHW. (2014). Australia's health 2014. Canberra, Australia: Australian Institute of Health and Welfare. 
APPG. (2010). Inquiry into the effectiveness and cost-effectiveness of tobacco control: Submission to the 2010 Spending Review and Public Health White Paper Consultation process. London, United Kingdom: All Party Parliamentary Group on Smoking and Health.

ASH. (2016). Health inequalities and smoking. Action on Smoking and Health. Available at http://www.ash.org.uk/current-policy-issues/health-inequalities/smoking-and-healthinequalities

Baldwin, R. (2014). From regulation to behaviour change: giving nudge the third degree. The Modern Law Review, 77(6), 831-857.

Bartholomew, L., Parcel, G., Kok, G., Gottlieb, N., \& Fernandez, M. E. (2011). Planning health promotion programmes: An intervention mapping approach (3rd ed.). San Francisco: Jossey-Bass.

BMA. (2012). Behaviour change, public health and the role of the state-BMA position statement. London: British Medical Association.

Bonell, C., McKee, M., Fletcher, A., Wilkinson, P., \& Haines, A. (2011). *One nudge forward, two steps back[http://dx.doi.org/10.1136/bmj.d401]*. BMJ, 342, d401.

Borland, R., Yong, H.-H., Wilson, N., Fong, G. T., Hammond, D., Cummings, K. M., et al. (2009). *How reactions to cigarette packet health warnings influence quitting: Findings from the ITC Four-Country survey[http://dx.doi.org/10.1111/j.13600443.2009.02508.x]*. Addiction, 104(4), 669-675.

Boyd, K. A., Briggs, A. H., Bauld, L., Sinclair, L., \& Tappin, D. (2015). *Are financial incentives cost-effective to support smoking cessation during pregnancy? [http://dx.doi.org/10.1111/add.13160]*Addiction, 111, 360-370.

Bussieres, A. E., Patey, A. M., Francis, J., Sales, A. E., \& Grimshaw, J. M. (2012). Identifying factors likely to influence compliance with diagnostic imaging guideline 
recommendations for spine disorders among chiropractors in North America: A focus group study using the Theoretical Domains Framework. Implementation Science, 7(1), 82.

Cabinet Office Behavioural Insights Team. (2010). Applying behavioural insight to health. London: Cabinet Office Behavioural Insights Team.

Cane, J., O’Connor, D., \& Michie, S. (2012). *Validation of the Theoretical Domains framework for use in behaviour change and implementation research[http://dx.doi.org/10.1186/1748-5908-7-37]*. Implementation Science, 7(37).

Cappuccino, F. P., \& Capewell, S. (2010). *How to cut down salt intake in populations[http://dx.doi.org/10.1136/hrt.2010.209023]*. Heart, 96(23), 1863-1864.

CDC. (2013). Ten great public health achievements in the 20th century. Centers for Disease Control. Available at http://www.cdc.gov/about/history/tengpha.htm

Connell, L. A., McMahon, N. E., Redfern, J., Watkins, C. L., \& Eng, J. J. (2015).

*Development of a behaviour change intervention to increase upper limb exercise in stroke rehabilitation[http://dx.doi.org/10.1186/s13012-015-0223-3]*. Implementation Science, 10, 34.

Craig, P., Dieppe, P., Macintyre, S., Michie, S., Nazareth, I., \& Petticrew, M. (2008). *Developing and evaluating complex interventions: The new Medical Research Council guidance[http://dx.doi.org/10.1136/bmj.a1655]*. British Medical Journal, 337(a1655).

Curtis, K. E., Lahiri, S., \& Brown, K. E. (2015). Targeting parents for childhood weight management: development of a theory-driven and user-centered healthy eating app. JMIR Mhealth Uhealth, 3(2), e69.

Davis, R., Campbell, R., Hildon, Z., Hobbs, L., \& Michie, S. (2015). *Theories of behaviour and behaviour change across the social and behavioural sciences: A scoping 
review[http://dx.doi.org/10.1080/17437199.2014.941722]*. Health Psychology Review, 9(3), 323-344.

Department of Health. (2014). Living well for longer: National support for local action to reduce premature avoidable mortality. London: Department of Health.

Dombrowski, S. U., Sniehotta, F. F., Avenell, A., Johnston, M., MacLennan, G., \& AraujoSoares, V. (2012). *Identifying active ingredients in complex behavioural interventions for obese adults with obesity-related co-morbidities or additional risk factors for comorbidities: A systematic review[http://dx.doi.org/10.1080/17437199.2010.513298]*. Health Psychology Review, 6(1), 7-32.

Duncan, E. M., Francis, J., Johnston, M., Davey, P., Maxwell, S., McKay, G. A., et al. (2012). Learning curves, taking instructions, and patient safety: Using a theoretical domains framework in an interview study to investigate prescribing errors among trainee doctors. Implementation Science, 7(1), 86.

Fleming, A., Bradley, C., Cullinan, S., \& Byrne, S. (2014). *Antibiotic prescribing in longterm care facilities: A qualitative multidisciplinary investigation[http://dx.doi.org/10.1136/bmjopen-2014-006442]*. BMJ OPen, 4(11), $\mathrm{e} 006442$.

Francis, J., O’Connor, D., \& Curran, J. A. (2012). *Theories of behaviour change synthesised into a set of theoretical groupings: Introducing a thematic series on the theoretical domains framework. Implementation Science, 7(1), 35.

French, D. P., Olander, E. K., Chisholm, A., \& Sharry, J. Mc. (2014). *Which behaviour change techniques are most effective at increasing older adults' self-efficacy and physical activity behaviour? A systematic review[http://dx.doi.org/10.1007/s12160-014-9593-z]*. Annals of Behavioral Medicine, 48, 225-234. 
French, S. D., Green, S. E., O’Connor, D. A., McKenzie, J. E., Francis, J., Michie, S., et al. (2012). *Developing theory-informed behaviour change interventions to implement evidence into practice: A systematic approach using the Theoretical Domains Framework[http://dx.doi.org/10.1186/1748-5908-7-38]*. Implementation Science, 7, 38. Fuller, C., Michie, S., Savage, J., McAteer, J., Besser, S., Charlett, A., et al. (2012). The Feedback Intervention Trial (FIT)_-Improving hand-hygiene compliance in UK healthcare workers: A stepped wedge cluster randomised controlled trial. PLoS One, $7(10)$, e41617.

Fulton, E. A., Brown, K., Kwah, K., \& Wild, S. (2016). *Stop-app: Using the Behaviour Change Wheel to develop an app to increase uptake and attendance at NHS Stop Smoking Services[http://dx.doi.org/10.3390/healthcare4020031]*. Healthcare 4(2), 31.

Gardner, B. (2015). *A review and analysis of the use of "habit" in understanding, predicting and influencing health-related behaviour[http://dx.doi.org/10.1080/17437199.2013.876238]*. Health Psychology Review, 9(3), 277-295.

Gardner, B., Smith, L., Lorencatto, F., Hamer, M., \& Biddle, B. J. (2016). *How to reduce sitting time? A review of behaviour change strategies used in sedentary behaviour reduction interventions among adults[http://dx.doi.org/10.1080/17437199.2015.1082146]*. Health Psychology Review, 10(1), 89-112.

Hallsworth, M., Chadborn, T., Sallis, A., Sanders, M., Berry, D., Greaves, F., et al. (2016). *Provision of social norm feedback to high prescribers of antibiotics in general practice: A pragmatic national randomised controlled trial[http://dx.doi.org/10.1016/S01406736(16)00215-4]*. Lancet, 387(10029), 1743-1752. 
Higgins, S. T., Washio, Y., Heil, S. H., Solomon, L. J., Gaalema, D. E., Higgins, T. M., et al. (2012). *Financial incentives for smoking cessation among pregnant and newly postpartum women[http://dx.doi.org/10.1016/j.ypmed.2011.12.016]*. Preventive Medicine, 55(Suppl), S33-S40.

Hinman, A. (1999). *Eradication of vaccine-preventable diseases[http://dx.doi.org/10.1146/annurev.publhealth.20.1.211]*. Annual Review of Public Health, 20, 211-229.

Hiscock, R., \& Bauld, L. (2013). Stop smoking services and health inequalities. In A. McEwen (Ed.), Stop smoking services and health inequalities, 10, 1-7. London: National Centre for Smoking Cessation and Training.

Holmes, K. K., Levine, R., \& Weaver, M. (2004). Effectiveness of condoms in preventing sexually transmitted infections. Bulletin of the World Health Organization, 82(6), 454461.

House of Lords. (2011). Behaviour change (2nd Report of Session 2010-2012). London: House of Lords, Science and Technology Select Committee.

Institute for Government. (2010). MINDSPACE: Influencing behaviour through public policy. London: Institute for Government, the Cabinet Office.

Ito, K., Shrank, W., Avron, J., Patrick, A. R., Brennan, T. A., Antman, E. M., et al. (2012). *Comparative cost-effectiveness of interventions to improve medication adherence after myocardial infarction[http://dx.doi.org/10.1111/j.1475-6773.2012.01462.x]*. Health Services Research, 47(6), 2097-2117.

Johnson, N. B., Hayes, L. D., Brown, K., Hoo, E. C., \& Ethier, K. A. (2014). CDC National Health Report: Leading causes of morbidity and mortality and associated behavioral risk and protective factors-United States, 2005-2013. Morbidity and Mortality Weekly Report, 63(4), 3-27. 
Kotz, D., Brown, J., \& West, R. (2013). *“Real-world" effectiveness of smoking cessation treatments: a population study[http://dx.doi.org/10.1111/add.12429]*. Addiction, 109(3), $491-499$.

Kotz, D., \& West, R. (2009). *Explaining the social gradient in smoking cessation: It's not in the trying, but in the succeeding[http://dx.doi.org/10.1136/tc.2008.025981]*. Tobacco Control, 18, 43-46.

Lara, J., Evans, E. H., O’Brien, N., Moynihan, P. J., Meyer, T. D., Adamson, A. J., et al. (2014). *Associations of behaviour change techniques with effectiveness of dietary interventions among adults of retirement age: A systematic review and meta-analysis of randomised controlled trials[http://dx.doi.org/10.1186/1741-7015-12-60]*. BMC Medicine, 12(60), 177.

Larsen, K. R., Michie, S., Hekler, E. B., Gibson, B., Spruijt-Metz, D., Ahern, D., et al. (2017). *Behavior change interventions: The potential of ontologies for advancing science and practice[http://dx.doi.org/10.1007/s10865-016-9768-0]*. Journal of Behavioral Medicine, 40(1), 6-22.

Llor, C., Hernandez, S., Bayona, C., Moragas, A., Sierra, N., Hernandez, M., et al. (2013). *A study of adherence to antibiotic treatment in ambulatory respiratory infections[http://dx.doi.org/10.1016/j.ijid.2012.09.012]*. International Journal of Infectious Diseases, 17(3), e168-e172.

Local Government Association. (2013). Changing behaviours in public health. To nudge or to shove? London: Local Government Association.

Logan, R. F. A., Patnick, J., Nickerson, C., Coleman, L., Rutter, M. D., \& von Wagner, C. (2011). *Outcomes of the Bowel Cancer Screening Programme (BCSP) in England after the first 1 million tests. [http://dx.doi.org/10.1136/gutjnl-2011-300843]*. Gut, 61(10), 1439-1446 
Lumley, J., Chamberlain, C., Dowswell, T., Oliver, S., Oakley, L., \& Watson, L. (2009).

*Interventions for promoting smoking cessation during

pregnancy[http://dx.doi.org/10.1002/14651858.CD001055.pub3]*. Cochrane Database of Systematic Reviews 8(3).

Marteau, T. M., Ogilvie, D., Roland, M., Suhrcke, M., \& Kelly, M. P. . (2011). *Judging nudging: Can nudging improve population health?

[http://dx.doi.org/10.1136/bmj.d228]*BMJ, 342, d228.

Matjasko, J. L., Cawley, J. H., Baker-Goering, M. M., \& Yokum, D. V. (2016). *Applying behavioral economics to public health policy: Illustrative examples and promising directions[http://dx.doi.org/10.1016/j.amepre.2016.02.007]*. American Journal of Preventive Medicine, $50(5$ Suppl 1), S13-S19.

Michie, S., Abraham, C., Whittington, C., McAteer, J., \& Gupta, S. (2009). *Effective techniques in healthy eating and physical activity interventions: A metaregression[http://dx.doi.org/10.1037/a0016136]*. Health Psychology, 28(6), 690-701.

Michie, S., Ashford, S., Sniehotta, F. F., Dombrowski, S. U., Bishop, A., \& French, D. P. (2011). *A refined taxonomy of behaviour change techniques to help people change their physical activity and healthy eating behaviours: The CALO-RE taxonomy[http://dx.doi.org/10.1080/08870446.2010.540664]*. Psychology \& Health, 26(11), 1479-1498.

Michie, S., Atkins, L., \& West, R. (2014). The Behaviour Change Wheel: A guide to designing interventions. London: Silverback Publishing.

Michie, S., Hyder, N., Walia, A., \& West, R. (2011). *Development of a taxonomy of behaviour change techniques used in individual behavioural support for smoking cessation[http://dx.doi.org/10.1016/j.addbeh.2010.11.016]*. Addictive Behaviors, 36(4), $315-319$. 
Michie, S., \& Johnston, M. (2013). Behavior change techniques. In J. R. Turner (Ed.), Encyclopedia of behavioral medicine (pp. 182-187). New York: Springer.

Michie, S., Johnston, M., Abraham, C., Lawton, R., Parker, D., \& Walker, A. (2005). *Making psychological theory useful for implementing evidence based practice: A consensus approach[http://dx.doi.org/10.1136/qshc.2004.011155]*. Quality \& Safety in Health Care, 14(1), 26-33.

Michie, S., Richardson, M., Johnston, M., Abraham, C., Francis, J., Hardeman, W., et al. (2013). *The Behavior Change Technique Taxonomy (v1) of 93 hierarchically clustered techniques: building an international consensus for the reporting of behavior change interventions[http://dx.doi.org/10.1007/s12160-013-9486-6]*. Annals of Behavioral Medicine, 46(1), 81-95.

Michie, S., van Stralen, M. M., \& West, R. (2011). *The Behaviour Change Wheel: A new method for characterising and designing behaviour change interventions[http://dx.doi.org/10.1186/1748-5908-6-42]*. Implementation Science, $6(42)$.

Michie, S., \& West, R. (2013). *Behaviour change theory and evidence: A presentation to Government[http://dx.doi.org/10.1080/17437199.2011.649445]*. Health Psychology Review, 7(1), 1-22.

Michie, S., Whittington, C., Hamoudi, Z., Zarnani, F., Tober, G., \& West, R. (2012).

*Identification of behaviour change techniques to reduce excessive alcohol consumption[http://dx.doi.org/10.1111/j.1360-0443.2012.03845.x]*. Addiction, 107(8), 1431-1440.

Michie, S., Wood, C. E., Johnston, M., Abraham, C., Francis, J. J., \& Hardeman, W. (2015). *Behaviour change techniques: The development and evaluation of a taxonomic method for reporting and describing behaviour change interventions (a suite of five studies 
involving consensus methods, randomised controlled trials and analysis of qualitative data). [http://dx.doi.org/10.3310/hta19990]*Health Technology Assessment, 19(99), 1188.

NICE. (2007). Behaviour change at population, community and individual levels. London: National Institute for Health and Clinical Excellence.

NICE. (2014). Behaviour change: Individual approaches. London: National Institute for Health and Clinical Excellence.

O’Neill, J. (2014). Antimicrobial resistance: Tackling a crisis for the health and wealth of nations. London: U.K. Government

Olander, E. K., Fletcher, H., Williams, S., Atkinson, L., Turner, A., \& French, D. P. (2013). What are the most effective techniques in changing obese individuals' physical activity self-efficacy and behaviour: A systematic review and meta-analysis. International Journal of Behavioural Nutrition and Physical Activity, 10(1), 29.

Osborn, D., Burton, A., Walters, K., Nazareth, I., Heinkel, S., Atkins, L., et al.. (2016). *Evaluating the clinical and cost effectiveness of a behaviour change intervention for lowering cardiovascular disease risk for people with severe mental illnesses in primary care (PRIMROSE study): Study protocol for a cluster randomised controlled trial[http://dx.doi.org/10.1186/s13063-016-1176-9]*. Trials, 17, 80.

Ownby, R., Waldrop-Valverde, D., Jacobs, R. J., Acevedo, A., \& Caballero, J. (2013). *Cost effectiveness of computer-delivered intervention to improve HIV medication adherence. [http://dx.doi.org/10.1186/1472-6947-13-29]*. BMC Medical Informatics and Decision Making, 13, 29

Peters, G.-J. Y., Ruiter, R. A. C., \& Kok, G. (2013). *Threatening communication: A critical re-analysis and a revised meta-analytic test of fear appeal 
theory[http://dx.doi.org/10.1080/17437199.2012.703527]*. Health Psychology Review, 7(Suppl 1), S8-S31.

Robinson, E., Higgs, S., Daley, A. J., Jolly, K., Lycett, D., Lewis, A., et al. (2013).

*Development and feasibility testing of a smart phone based attentive eating intervention[http://dx.doi.org/10.1186/1471-2458-13-639]*. BMC Public Health, 13(1), 639.

Rubinstein, H., Marcu, A., Yardley, L., \& Michie, S. (2015). *Public preferences for vaccination and antiviral medicines under different pandemic flu outbreak scenarios[http://dx.doi.org/10.1186/s12889-015-1541-8]*. BMC Public Health, 15, 190.

Sackett, D. L., Rosenberg, W. M. C., Gray, J. A. M, Haynes, R. B., \& Richardson, W. S. (1996). *Evidence based medicine: What it is and what it isn't[http://dx.doi.org/10.1136/bmj.312.7023.71]*. BMJ, 312, 71.

Shahab, L., \& West, R. (2010). *Public support in England for a total ban on the sale of tobacco products[http://dx.doi.org/10.1136/tc.2009.033415]*. Tobacco Control, 19, 143147.

Shahab, L., West, R., \& McNeill, A. (2011). *A randomized, controlled trial of adding expired carbon monoxide feedback to brief stop smoking advice: Evaluation of cognitive and behavioral effects[http://dx.doi.org/10.1037/a0021821]*. Health Psychology, 30(1), $49-57$.

Sinnott, C., Mercer, S. W., Payne, R. A., Duerden, M., Bradley, C. P., \& Byrne, M. (2015). *Improving medication management in multimobidity: Development of the MultimorbiditY COllaborative Medication Review And DEcision Making (MY COMRADE) intervention using the Behaviour Change Wheel[http://dx.doi.org/10.1186/s13012-015-0322-1]*. Implementation Science, 10, 132. 
Stead, L. F., \& Lancaster, T. (2012). *Combined pharmacotherapy and behavioural interventions for smoking cessation [http://dx.doi.org/10.1002/14651858.CD008286.pub2]*. Cochrane Database of Systematic Reviews, 12, CD008286.

Steinmo, S. H., Michie, S., Fuller, C., Stanley, S., Stapleton, C., \& Stone, S. P. (2016). *Bridging the gap between pragmatic intervention design and theory: Using behavioural science tools to modify an existing quality improvement programme to implement “Sepsis Six.” [http://dx.doi.org/10.1186/s13012-016-0376-8]*Implementation Science, $11,14$.

Tappin, D., Bauld, L., Purves, D., Boyd, K., Sinclair, L., MacAskill, S., et al. (2015). *Financial incentives for smoking cessation in pregnancy: Randomised controlled trial[http://dx.doi.org/10.1136/bmj.h134]*. BMJ, 350(h134).

Tavender, E. J., Bosch, M., Gruen, R. L., Green, S. E., Michie, S., Brennan, S. E., et al. (2015). *Developing a targeted, theory-informed implementation intervention using two theoretical frameworks to address health professional and organisational factors: A case study to improve the management of mild traumatic brain injury in the emergency department[http://dx.doi.org/10.1186/s13012-015-0264-7]*. Implementation Science, 10(74).

Templeton, A. R., Young, L., Bish, A., Gnich, W., Cassie, H., Treweek, S., et al. (2015). *Patient-, organization-, and system-level barriers and facilitators to preventive oral health care: A convergent mixed-methods study in primary dental care[http://dx.doi.org/10.1186/s13012-015-0366-2]*. Implementation Science, 11, 5.

Thaler, R., \& Sunstein, C. (2008). Nudge: Improving decisions about health, wealth and happiness. New Haven, CT: Yale University Press. 
Thomson, G., Morgan, H., Crossland, N., Bauld, L., Dykes, F., \& Hoddinott, P. (2014).

*Unintended consequences of incentive provision for behaviour change and maintenance around childbirth[http://dx.doi.org/10.1371/journal.pone.0111322]*. PLoS One, 9(10), e111322.

Tombor, I., Neale, J., Shahab, L., Ruiz, M., \& West, R. (2015). *Healthcare providers' views on digital smoking cessation interventions for pregnant women [http://dx.doi.org/10.1017/jsc.2014.6]*. Journal of Smoking Cessation, 10(2), 116-123.

Tombor, I., Shahab, L., Brown, J., Crane, D., Michie, S., \& West, R. (2016). *Development of SmokeFree Baby: A smoking cessation smartphone app for pregnant smokers[http://dx.doi.org/10.1007s13142-016-0438-0]*. Translational Behavioral Medicine: Practice, Policy and Research, 6(4), 533-545.

Tzelepis, F., Paul, C. L., Wiggers, J., Kypri, K., Bonevski, B., McElduff, P., et al. (2015). *Targeting multiple health risk behaviours among vocational education students using electronic feedback and online and telephone support: Protocol for a cluster randomised trial[http://dx.doi.org/10.1186/s12889-015-1898-8]*. BMC Public Health, 15, 550. van Genugten, L., Dusseldorp, E., Webb, T. L., \& van Empelen, P. (2016). Which combinations of techniques and modes of delivery in Internet-based interventions effectively change health behavior? A metaanalysis[http://dx.doi.org/10.2196/jmir.4218]*. JMIR Mhealth Uhealth, 18(6), e155.

Verplanken, B., \& Wood, W. (2006). *Interventions to break and create consumer habits. Journal of Public Policy and Marketing, 25(1), 90-103.

Webb, T. L., Joseph, J., Yardley, L., \& Michie, S. (2010). *Using the Internet to promote health behaviour change: a systematic review and meta-analysis of the impact of theoretical basis, use of behaviour change techniques, and mode of delivery on 
efficacy[http://dx.doi.org/10.2196/jmir.1376]*. Journal of Medical Internet Research, 12(1), e4.

West, R., Evans, A., \& Michie, S. (2011). *Behavior change techniques used in groupbased behavioral support by the English stop-smoking services and preliminary assessment of association with short-term quit outcomes[http://dx.doi.org/10.1093/ntr/ntr120]*. Nicotine \& Tobacco Research, 13(12), $1316-1320$.

West, R., May, S., West, M., Croghan, E., \& McEwen, A. (2013). *Performance of English stop smoking services in first 10 years: Analysis of service monitoring data[http://dx.doi.org/10.1136/bmj.f4921]*. BMJ, 347(f4921).

West, R., Raw, M., McNeill, A., Stead, L., Aveyard, P., Britton, J., et al. (2015).

*Healthcare interventions to promote and assist tobacco cessation: A review of efficacy, effectiveness and affordability for use in national guideline development[http://dx.doi.org/10.1111/add.12998]*. Addiction, 110(9), 1388-1403.

Williams, S. L., \& French, D. P. (2011). *What are the most effective intervention techniques for changing physical activity self-efficacy and physical activity behaviourand are they the same? [http://dx.doi.org/10.1093/her/cyr005]*Health Education Research, 26(2), 308-322.

Wood, W., \& Rünger, D. (2016). *Psychology of habit[http://dx.doi.org/10.1146/annurevpsych-122414-033417]. Annual Review of Psychology, 67, 289-314.

World Health Organization. (2009). Global health risks: Mortality and burden of diseases attributable to selected major risks. Geneva: World Health Organization. 
Electronic Sources

*The UCL Centre for Behaviour Change and further resources for topics mentioned in this article [http://www.ucl.ac.uk/behaviour-change]*

*Soundcloud is a source for podcasts about behavior change[https://soundcloud.com/uclbehaviour-change $]^{*}$

*BCT Taxonomy v1 online training[http://www.bct-taxonomy.com]*

Further Reading

Jepson, R. G., Harris, F. M., Platt, S., Tannahill, C. (2010). *The effectiveness of interventions to change six health behaviours: A review of reviews[http://dx.doi.org/10.1186/1471-2458-10-538]*. BMC Public Health, 10, 538.

Kok, G., Gottlieb, N. H., Peters, G.-J. Y., Dolan Mullen, P., Parcel, G. S., Ruiter, R. A. C. et al. (2016). *A taxonomy of behaviour change methods: An intervention mapping approach[http://dx.doi.org/10.1080/17437199.2015.1077155]*. Health Psychology Review, 10(3), 297-312.

Peters, G. J., de Bruin, M., Crutzen, R. (2015). *Everything should be as simple as possible, but no simpler: Towards a protocol for accumulating evidence regarding the active content of health behaviour change interventions[http://dx.doi.org/10.1080/17437199.2013.848409]*. Health Psychology Review, 9(1), 1-14.

Presseau, J., Johnston, M., Heponiemi, T., Elovainio, M., Francis, J. J., Eccles, M. P. et al. (2014). *Reflective and automatic processes in health care professional behaviour: A dual process model tested across multiple behaviours[http://dx.doi.org/10.1007/s12160014-9609-8]*. Annals of Behavior Medicine, 48, 347-358. 
Riley, W. T. \& Rivera, D. E. (2014). *Methodologies for optimizing behavioral interventions: Introduction to special section[http://dx.doi.org/10.1007/s13142-014-02810]*. Translational Behavioral Medicine: Practice, Policy and Research, 4(3), 234-237. Spruijt-Metz, D., Hekler, E., Saranummi, N., Intille, S., Korhonen, I., Nilsen, W. et at. (2015). *Building new computational models to support health behavior change and maintenance: New opportunities in behavioral research[http://dx.doi.org/10.1007/s13142015-0324-1]*. Translational Behavioral Medicine: Practice, Policy and Research, 5(3), $335-346$.

Tate, D. F., Lytle, L. A., Sherwood, N. E., Haire-Joshu, D., Matheson, D., Moore, S. M. et al. (2016). *Deconstructing interventions: Approaches to studying behavior change techniques across obesity interventions[http://dx.doi.org/10.1007/s13142-015-0369-1]*. Translational Behavioral Medicine: Practice, Policy and Research, 6(2), 236-243.

\section{Ildiko Tombor and Susan Michie}

Figure 1. The Behavior Change Wheel (Michie et al., 2011)

Table 1 Linking Evidence-Based Principles of Behavior Change with Components of the COM-B Model

\begin{tabular}{|c|c|c|c|c|c|c|}
\hline \multirow{2}{*}{$\begin{array}{l}\text { Evidence-Based Principles of Behavior } \\
\text { Change }\end{array}$} & \multicolumn{2}{|c|}{ Capability } & \multicolumn{2}{|c|}{ Opportunity } & \multicolumn{2}{|c|}{ Motivation } \\
\hline & 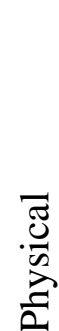 & 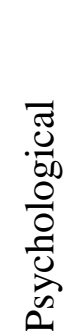 & 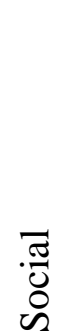 & 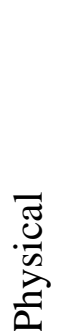 & :节 & 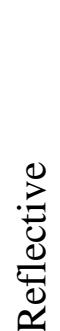 \\
\hline 1. Knowledge and outcome expectancies & & $\mathrm{X}$ & & & & $\mathrm{X}$ \\
\hline 2. Personal relevance & & & & & & $\mathrm{X}$ \\
\hline
\end{tabular}




\begin{tabular}{|l|l|l|l|l|l|l|}
\hline 3. Positive affective attitudes & & & & & $\mathrm{X}$ & \\
\hline 4. Descriptive norms & & & $\mathrm{X}$ & & & $\mathrm{X}$ \\
\hline 5. Subjective norms & & & $\mathrm{X}$ & & & $\mathrm{X}$ \\
\hline 6. Personal and moral norms & & & & & & $\mathrm{X}$ \\
\hline 7. Self-efficacy & & & & & & $\mathrm{X}$ \\
\hline 8. Intention/goal setting and the & & $\mathrm{X}$ & & & & $\mathrm{X}$ \\
formation of concrete plans & & & & & & \\
\hline 9. Behavioral contracts & & & $\mathrm{X}$ & & & $\mathrm{X}$ \\
\hline 10. Social relationships & & & $\mathrm{X}$ & & & \\
\hline 11. Relapse prevention & & $\mathrm{X}$ & & & & \\
\hline
\end{tabular}


Table 2 Linking the Theoretical Domains Framework with Evidence-Based Principles of Behavior Change and the COM-B Model

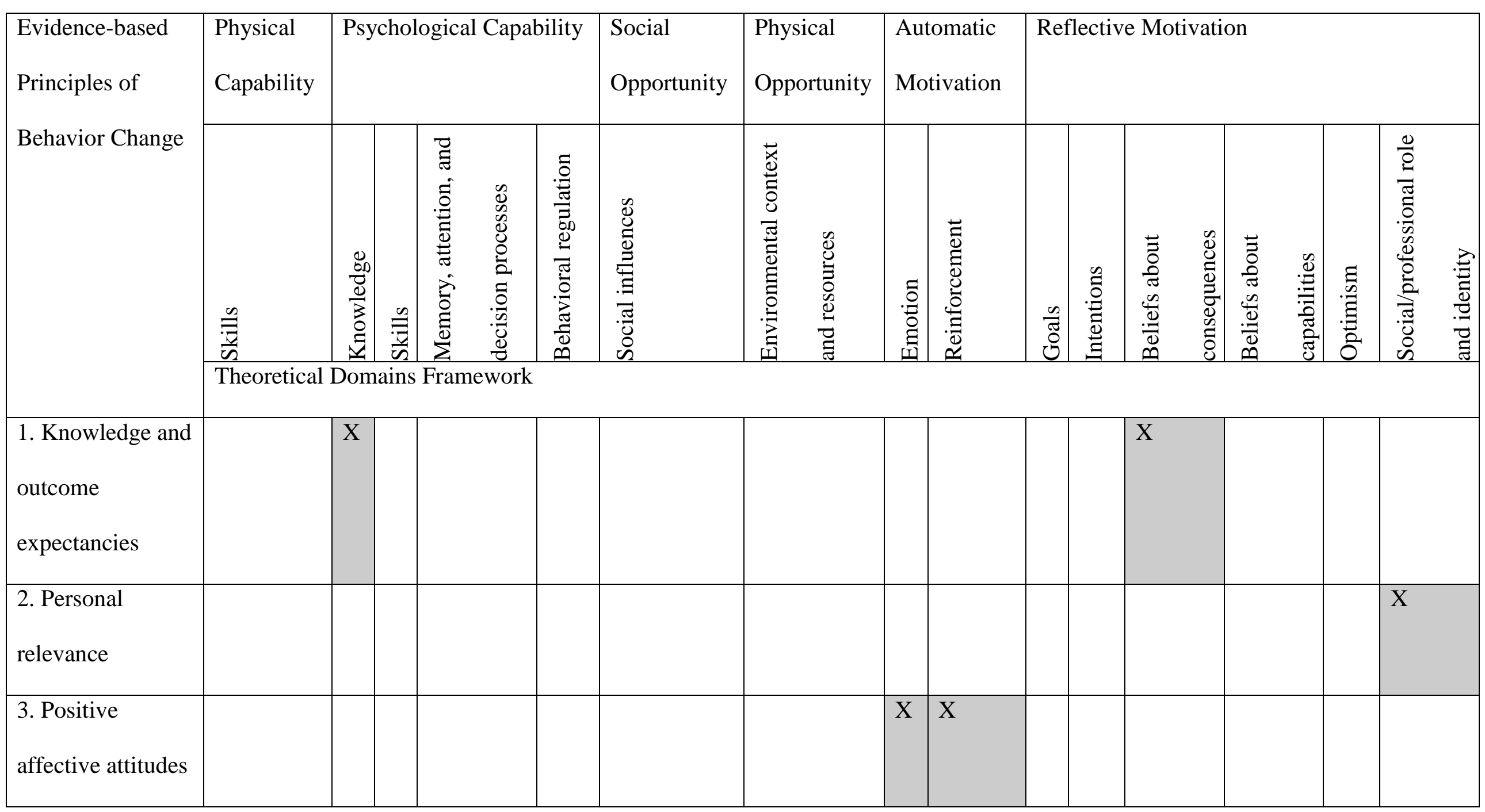




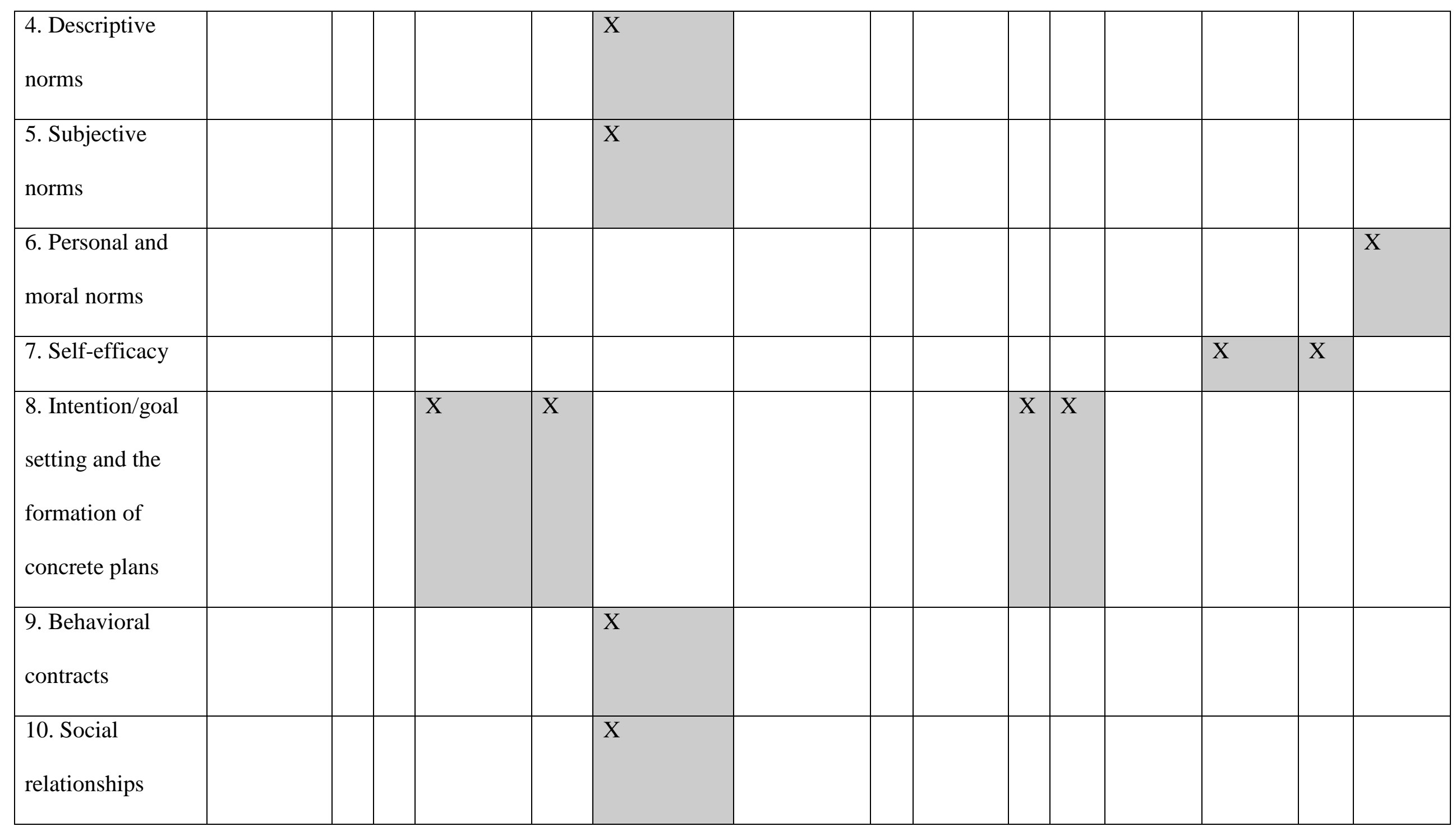




\begin{tabular}{|l|l|l|l|l|l|l|l|l|l|l|l|l|l|}
\hline 11. Relapse \\
prevention
\end{tabular}


Table 3 Linking Intervention Functions in the Behavior Change Wheel with EvidenceBased Principles of Behavior Change

\begin{tabular}{|c|c|c|c|c|c|c|c|c|c|}
\hline \multirow{2}{*}{$\begin{array}{l}\text { Evidence-Based } \\
\text { Principles of } \\
\text { Behavior Change }\end{array}$} & \multicolumn{9}{|c|}{ Intervention Functions } \\
\hline & . & 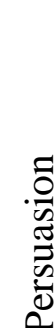 & 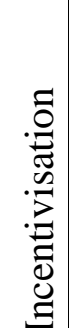 & . & 先 & 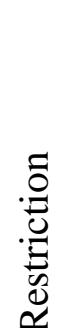 & 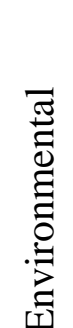 & $\begin{array}{l}\stackrel{60}{9} \\
\stackrel{8}{0} \\
\frac{8}{2}\end{array}$ & $\begin{array}{l}\overrightarrow{0} \\
\frac{0}{0} \\
\frac{\overrightarrow{0}}{0} \\
\text { जี }\end{array}$ \\
\hline $\begin{array}{l}\text { 1. Knowledge and } \\
\text { outcome } \\
\text { expectancies }\end{array}$ & $\mathrm{X}$ & & & & & & & & \\
\hline $\begin{array}{l}\text { 2. Personal } \\
\text { relevance }\end{array}$ & & $\mathrm{X}$ & & & & & & $\mathrm{X}$ & \\
\hline $\begin{array}{l}\text { 3. Positive } \\
\text { affective attitudes }\end{array}$ & & $\mathrm{X}$ & $\mathrm{X}$ & & & & & $\mathrm{X}$ & \\
\hline $\begin{array}{l}\text { 4. Descriptive } \\
\text { norms }\end{array}$ & & $\mathrm{X}$ & & & & $\mathrm{X}$ & $\mathrm{X}$ & $\mathrm{X}$ & \\
\hline $\begin{array}{l}\text { 5. Subjective } \\
\text { norms }\end{array}$ & & $\mathrm{X}$ & & & & $\mathrm{X}$ & $\mathrm{X}$ & $\mathrm{X}$ & \\
\hline $\begin{array}{l}\text { 6. Personal and } \\
\text { moral norms }\end{array}$ & & $\mathrm{X}$ & & & & & & $\mathrm{X}$ & \\
\hline 7. Self-efficacy & & $\mathrm{X}$ & & & $\mathrm{X}$ & & & & \\
\hline $\begin{array}{l}\text { 8. Intention/goal } \\
\text { setting and the } \\
\text { formation of } \\
\text { concrete plans }\end{array}$ & $\mathrm{X}$ & $\mathrm{X}$ & & & & & & & \\
\hline
\end{tabular}




\begin{tabular}{|l|l|l|l|l|l|l|l|l|l|}
\hline 9. Behavioral & & $\mathrm{X}$ & & & & & $\mathrm{X}$ & & \\
contracts & & & & & & & & & \\
\hline 10. Social & & $\mathrm{X}$ & & & & & $\mathrm{X}$ & & \\
relationships & & & & & & & & & \\
11. Relapse & $\mathrm{X}$ & & & & $\mathrm{X}$ & & & & $\mathrm{X}$ \\
\hline
\end{tabular}

